\title{
Geometallurgy study of the Catalão I Nelsonite bodies aiming to increase the niobium production
}

\author{
Leonardo Vasconcellos Rangel ${ }^{1 *}$ \\ Douglas Batista Mazzinghy ${ }^{1}$ \\ Gilberto Rodrigues da Silva ${ }^{1}$ \\ Felipe Seguin ${ }^{2}$ \\ Michelle Fernanda De Lira Teixeira ${ }^{2}$ \\ Sebastião Ubaldino Ferreira Junior ${ }^{2}$ \\ Caio Henrique Ribeiro Vieira ${ }^{2}$ \\ Wanderson Ferreira Borges Junior ${ }^{2}$ \\ Vinicius Campos Silva ${ }^{2}$ \\ Gabriel Rocha Dimitrov ${ }^{2}$
}

\begin{abstract}
Increasing the recovery of the niobium metal contained in the Nelsonite rocks presents a great challenge, considering the standards and the production targets of the China Molybdenum Company (CMOC) that produces phosphate and with tailings material, concentrate niobium minerals. At Chapadão mine, located in Goiás, a mid-west Brazil's state, the weathering profile reaches up to 100 meters and the ore is subdivided into three basic types, from top to bottom: Oxidized (OX), Top Micaceous (TM) and Base Micaceous (BM). In this study, samples from these three main bodies of Nelsonite were collected and tested in laboratory scale to identify which weathering level is more favourable to niobium concentrate production. In the niobium concentration process, there can be metal losses that can jeopardize the recovery of the niobium crystals. To evaluate these losses microscopy analysis was performed using samples from industrial plant survery. The results from flotation batch tests showed that BM presented the higher mass recovery and production capacity. According to the mineralogical results the main niobium losses were identified in the barite concentrate from apatite circuit and in the screening stage in the Niobium Plant feed. The batch test results showed that adjusting the cut size of the Niobium Plant there is a potential niobium recovery upgraded to $90 \%$ from Ba-pyrochlore, and, adding the barite concentrate product as an additional mass in the tailings feed, it will result together in more than $1 \mathrm{t}$ /day of niobium concentrate final product, reducing the losses and utilizing better the ore blend recovery potential.
\end{abstract}

Keywords: Geometallurgy; Mineralogy; Recovery; Tailings; Niobium; Pyrochlore.

\section{Introduction}

There are different definitions of geometallurgy in the literature, but most of them include geology, mining and metallurgy in some way [1-6]. Geometallurgy is a multidisciplinary approach and professionals from different areas need to work together to integrate the information available. A general definition for geometallurgy can be related to a tool aiming the integration of geological, mining, metallurgical and environmental data in a spatial model to forecast mineral processing plant production.

Nelsonites are known to be rocks of magmatic origin from correlated magmas with carbonatitic mantel plumes and are basically composed of magnetite, apatite and phlogopite, in this order of mineral predominance [7].
Although, depending on their temporal formation, it is possible to observe different structure, mineralogy, particle size or texture in different nelsonitic bodies, as showed in the Figure 1 [8].

This lithology contains various valuable minerals such as apatite (phosphate), magnetite (iron), pyrochlore (niobium), rare earth minerals and more rarely chalcopyrite-bornite (copper). The carbonate complexes of Araxá and Catalão are richest in which the nelsonitic rocks are mineralized in pyrochlore [9].

Chapadão mine, located in Goiás, a mid-west Brazil's state, is a mine belonging China Molybdenum Company (CMOC) and is the object of this study. Due to

${ }^{1}$ Curso de Pós-Graduação em Engenharia Metalúrgica, Materiais e de Minas - CPGEM, Universidade Federal de Minas Gerais - UFMG, Belo Horizonte, MG, Brasil.

${ }^{2}$ CMOC International Brazil (GO), Copebrás, Ouvidor, GO, Brasil.

*Corresponding author: Lvr.rangel@hotmail.com

2176-1523 (C) 2020. Rangel et al. Published by ABM. This is an Open Access article distributed under the terms of the Creative Commons Attribution License, which permits unrestricted use, distribution, and reproduction in any medium, provided the original work is properly cited. 


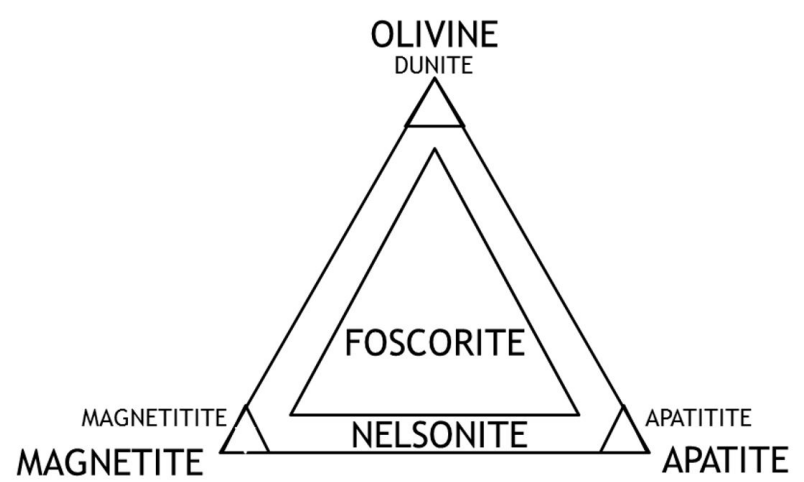

Figure 1. Foscoritic rocks diagram classification [8].

the great geological and mineralogical variability of the nelsonitic bodies, its behaviour in beneficiation processes is anomalous and depends on the pyrochlore mineralization, the nature of the grains of this mineral and its weathering degree. Thus, to ensure the recovery and production of niobium, it is necessary to characterize each type of nelsonite outcropping in order to ensure a better costbenefit for the company.

Previous geometallurgical studies mapped the principal nelsonite rock's and divided them in different groups based on grade and recoveries. These results made possible the selection of areas where metal niobium production potential was evident [10]. Rangel [11] built a simulator to forecast the production of Catalão mine based on mineralogical information of different lithologies blended in each pile that feeds the circuits. Statistical analysis showed a reasonable result obtained from the simulator when compared to industrial data.

This work was motivated by the imminent possibility of reducing the niobium losses in the phosphate circuit, which could add value to the concentrate of the niobium circuit, as well as updating the knowledge regarding the valuable mineral of interest. Several samples were taken from outcrops with different weathering conditions in the mine and were tested in laboratory scale. In addition, samples were collected from industrial circuits in order to understand the behaviour regarding the nature of niobium-bearing minerals present in the samples. The goal of the study was to characterize the nelsonite orebodies at different levels of weathering, to understand the metallurgical results and to identify niobium losses in the Phosphate circuits and propose solutions to recover it.

\section{Materials and methods}

\subsection{Samples}

Three samples of nelsonitic ores were collected at different weathering layers to perform laboratory flotation batch tests: oxidized (OX), top micaceous (TM) and base micaceous (BM). The samples were collected using the method of channels and trenches. The sample size corresponded to 5 meters of slope length, resulting in $50 \mathrm{~kg}$ of material. Each sample was quartered generating a $3 \mathrm{~kg}$ aliquot, which was the mass needed for the bench testing in the phosphate characterization route. These samples were collected and tested in laboratory scale to identify which weathering level is more favourable to niobium concentrate production, indicating the best material to constitutes the ore blend to feed the plant.

In the niobium concentration process, there can be metal losses that can impair the best recovery of the niobium crystals. Because of it, samples from industrial plant were also collected to investigate the possible niobium losses in each process stage using microscopy analysis. These other samples were collected to perform microscopy analysis: plant feed (PF), low intensity magnetic separation tailings (MT), barite concentrate (BC), apatite concentrate (AP) and Niobium Plant feed (NF). Each sample was quartered generating a $1 \mathrm{~kg}$ aliquot, which was the mass needed for the mineralogical testing in the microscopy lab.

\subsection{Mineralogical analyses}

The mineralogical analyses were conducted in the Microscopy Center at the Universidade Federal de Minas Gerais (UFMG). X-ray powder diffraction analyses were performed on a Scanning Electron Microscope - JEOL JSM - 6360LV equipped with high vacuum secondary electron detector, low and high vacuum backscattered electron detector, EDS (energy-dispersive X-ray spectroscopy) detector and an EBSD (electron backscatter diffraction) detector, plus a FEG - Quanta 200 FEI Scanning Electron Microscope equipped with a secondary electron detector, backscattered electron detector, transmitted electron detector (STEM), Pegasus: EDS and EBSD, operating at $30 \mathrm{kV}$ voltage, beam current greater than $100 \mathrm{nA}$, resolution of $1.6 \mathrm{~nm}$ at $30 \mathrm{kV}$ in high vacuum and ESEM-TM mode, $3.5 \mathrm{~nm}$ at $3 \mathrm{kV}$ at low vacuum, focal length: $3 \mathrm{~mm}$ to $99 \mathrm{~mm}, 12 \mathrm{x}$ magnification (at longest working distance) at 1,000,000x at high and low vacuum.

The mineralogical tests were performed to obtain the following results: mineral EDS spectra, a detailed imaging sequence, the sample modal mineral distribution, the estimated chemical composition of the constituent minerals, the liberation degree for the main minerals of interest, the mineral particle size distribution as well as the percentage distribution of the main chemical elements.

\subsection{Laboratory flotation batch tests}

Figure 2 shows the process flowsheet considered for this study.

Table 1 shows the reagents dosage and operational variables considered in the flotation tests. 


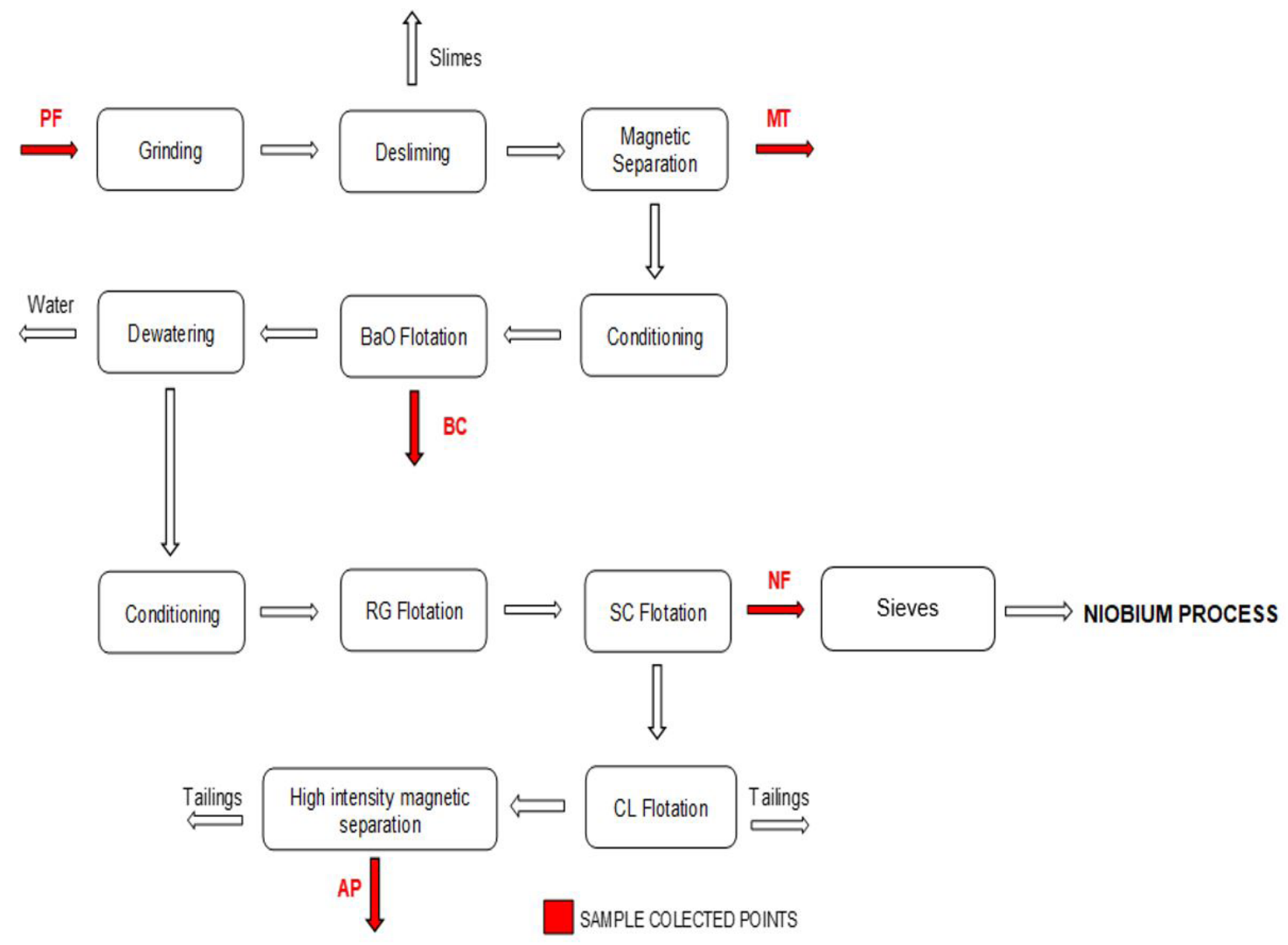

Figure 2. Laboratory batch test process flowsheet.

Table 1. Reagents dosage and operational variables considered in the flotation tests

\begin{tabular}{|c|c|c|c|c|c|c|c|c|}
\hline & Reagents & C1 & $\mathrm{BaO}$ & $\mathrm{C} 2$ & C3 & RG & SC & CL \\
\hline \multirow{5}{*}{ 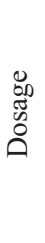 } & Starch $(\mathrm{mL})$ & 5 & & & 40 & & & \\
\hline & Lioflot (mL) & 6 & & & & & 10 & 10 \\
\hline & Flotinor-071 (mL) & 100 & & & & 5 & & \\
\hline & Lupromin (mL) & 4 & 0 & & & & & \\
\hline & Flotanol (mL) & 1 & & 0 & & & & \\
\hline \multirow{5}{*}{$\frac{\frac{\tilde{c}}{0}}{\frac{\pi}{\tilde{J}}}$} & Weight Solids (\%) & - & - & 47 & 47 & 47 & 30 & 30 \\
\hline & Rotation (rpm) & 1200 & 1200 & 1200 & 1200 & 1200 & 1200 & 1100 \\
\hline & $\mathrm{pH}$ & 9.5 & 9.5 & 9.5 & 9.5 & 9.5 & 9.5 & 9.5 \\
\hline & Conditioning (min.) & 03:00 & & 05:00 & $02: 30$ & & & \\
\hline & Flotation (min.) & & 02:00 & & & 02:00 & 01:30 & $01: 15$ \\
\hline
\end{tabular}

The collector and depressor dosages were fixed for all flotation tests. The conditioning was named as $\mathrm{C} 1$, $\mathrm{C} 2$ and $\mathrm{C} 3$.

The samples were ground to obtain $80 \%$ passing in $212 \mu \mathrm{m}\left(P_{80}\right)$, different size adopted in industrial circuit $(149 \mu \mathrm{m})$. This modification was made based on mineralogical analyses performed with the samples collected from industrial circuits in $20 \mathrm{~L}$ buckets.

\section{Results and discussion}

\subsection{Industrial plant survey}

Figure 3 shows a mineral map of a sample collected from the phosphate circuit feed. The colours represent the following minerals: Yellow - Apatite, Gray - Quartz, Red Ilmenite, Green - Hematite, Blue - Pyrochlore. 
According to the picture below it was possible to see that the principal ore minerals are in great majority free from intrusions and the apatite, quartz and pyrochlore minerals have a nice liberation grade percentage, what is favourable for the concentrate production mass.

Table 2 shows the mineral liberation grade of following flows: (MT) low intensity magnetic separation tailings, (NF) Niobium Plant feed, (BC) barite concentrate and (AP) apatite concentrate. Most of principal niobium minerals do not be liberated and recovered in MT because of the low percentage from free surface grain. The other stages presented more free surface grains that could be recovered.

Table 3 shows the mineralogical analysis for Ba-pyrochlore minerals according the cut size adopted. 100\% of Ba-pyrochlore have less than $212 \mu \mathrm{m}$, but the process cut-size was $149 \mu \mathrm{m}$. Considering an aperture in $149 \mu \mathrm{m}$, $60 \%$ of Ba-pyrochlore present in the material was discarded according to mineral release assays. Thus, changing the cut-size to $212 \mu \mathrm{m}$ would generate $90 \%$ of Ba-pyrochlore fed according to mineralogical analysis.

\subsection{Laboratory batch tests}

Table 4 shows the flotation results for OX, TM and $\mathrm{BM}$ weathering layers.

The OX showed a poor result for apatite, generating a concentrate with only $10 \%$ of mass recovery and a

Table 3. Mineralogical analysis for Ba-pyrochlore minerals according to size distribution

\begin{tabular}{ccc}
\hline \multirow{2}{*}{ Mineralogical Analysis } & \multicolumn{2}{c}{ Cut-size $(\boldsymbol{\mu m})$} \\
\cline { 2 - 3 } & $\mathbf{1 4 9}$ & $\mathbf{2 1 2}$ \\
\hline Ba-pyrochore lost $(\%)$ & 60.0 & 10.0 \\
Ba-pyrochore recovery (\%) & 40.0 & 90.0 \\
\hline
\end{tabular}

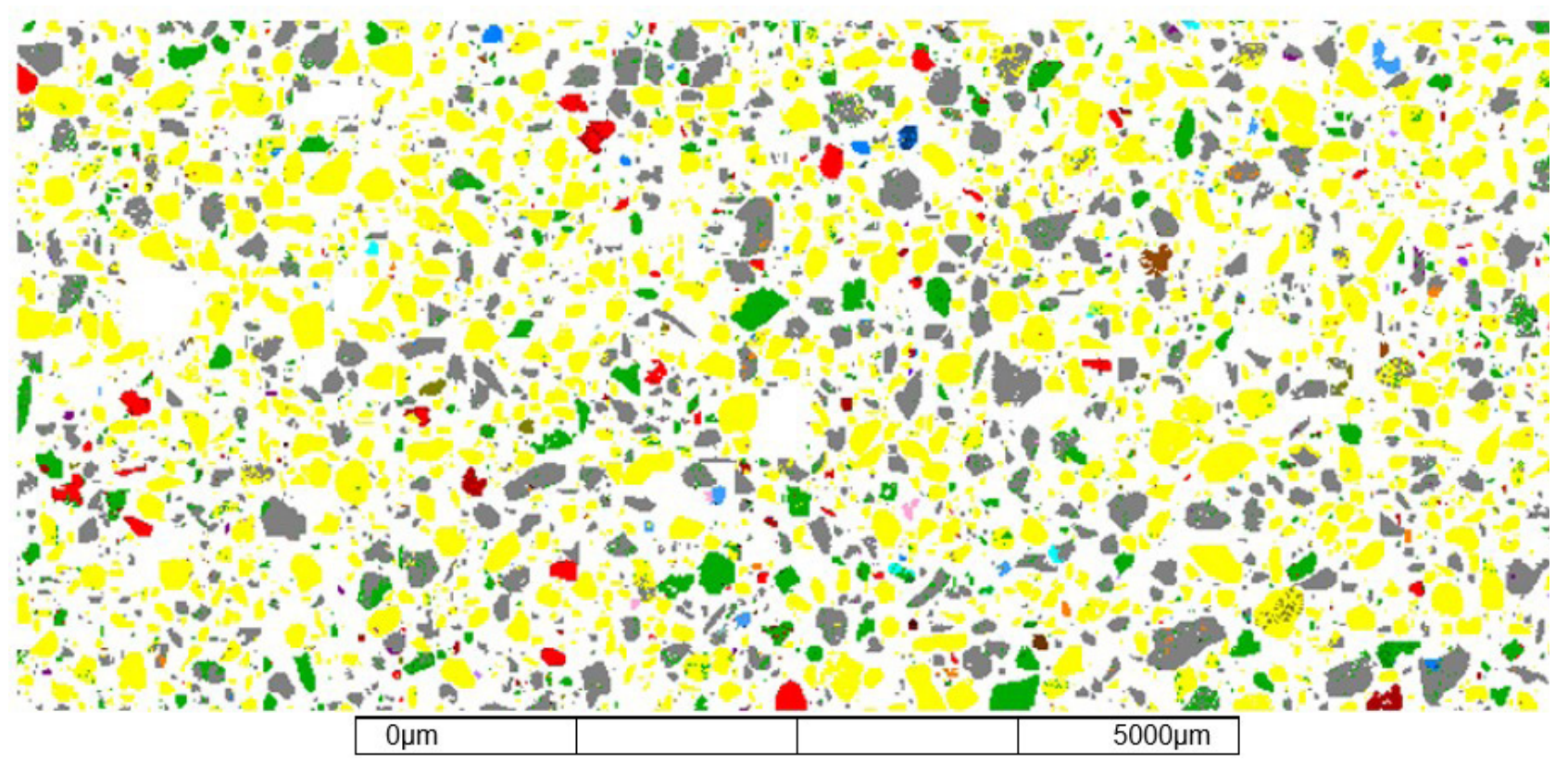

Figure 3. Mineral map of a sample collected from the phosphate circuit feed.

Table 2. Mineral Liberation Grade of (MT) low intensity magnetic separation tailings, (NF) Niobium Plant feed, (BC) barite concentrate and (AP) apatite concentrate

\begin{tabular}{|c|c|c|c|c|c|}
\hline Minerals & $\%$ & MT & NF & BC & $\mathbf{A P}$ \\
\hline \multirow{3}{*}{ Pyrochore } & Free & 4.0 & 9.0 & 24.0 & 20.0 \\
\hline & Binary & 39.0 & 44.0 & 64.0 & 48.0 \\
\hline & Ternary & 57.0 & 47.0 & 12.0 & 32.0 \\
\hline \multirow{3}{*}{ Ba-pyrochore } & Free & 2.0 & 71.0 & 32.0 & 50.0 \\
\hline & Binary & 46.0 & 14.0 & 32.0 & 39.0 \\
\hline & Ternary & 52.0 & 15.0 & 36.0 & 11.0 \\
\hline \multirow{3}{*}{ Zirconolite/Zirkelite } & Free & 1.0 & 48.0 & 37.0 & 26.0 \\
\hline & Binary & 5.0 & 25.0 & 28.0 & 52.0 \\
\hline & Ternary & 94.0 & 27.0 & 35.0 & 22.0 \\
\hline
\end{tabular}


global process recovery of only $39 \%$. For niobium, the target of this study, the product of interest, which is the scavenger tailings, presented a content of $0.33 \%$ from niobium oxide, which is relatively low considering the feed content targeted for the Niobium Plant. In addition, the mass that would be directed to the tailings was remarkably low, equivalent to only $4.5 \%$ of the total sample mass. In terms of the niobium distribution, the loss of the metal in the slimes and magnetic tailings was significantly high. Thus, it is possible to state that the OX will unlikely meet the necessary specifications for apatite concentration.

The TM showed an extremely poor result for apatite, generating a concentrate with only $10 \%$ mass recovery and a global process recovery only $37 \%$. For niobium, the scavenger tailings presented a $0.60 \%$ from niobium oxide grade, which is significant considering the tailings feed target. However, the mass that would be directed to the tailings was incredibly low, equivalent to $1.0 \%$ of the total mass of the sample. Similar to OX results, the TM will unlikely meet the necessary specifications for apatite concentration.

The BM showed a significant result for apatite, generating a concentrate with only $9 \%$ of mass recovery, but with overall recovery of 53\%. Regarding niobium, the scavenger tailings, presented an outstanding niobium content of $5.92 \%$, considering the feed content target for the Niobium Plant. However, the mass that would be directed to the tailings was low, equivalent to $5.0 \%$ of the total mass of the sample. Analysing the distribution of niobium it can be observed that the metal loss in the slimes and magnetic tailings was high but too much less than the other weathering levels samples.

Table 5 shows the differences between the cut-size considered in the initial project $(149 \mu \mathrm{m})$ and the cut-size adopted in batch flotation tests with the three samples of nelsonitic ores from different weathering layers $(212 \mu \mathrm{m})$. There is a potential increase of 0.46 $t /$ day of final niobium concentrate production changing the cut-size.

In terms of barite mineral concentrate, an interesting niobium loss was identified. The mineralogy showed that $50 \%$ of niobium in the feeding stage comes from Ba-pyrochlore and $32 \%$ of it is free. In particle size, $100 \%$ of Ba-pyrochlore is less than $38 \mu \mathrm{m}$.

Table 6 shows the capacity estimation considering the gain feed rate around $39 \mathrm{t} / \mathrm{h}$ that correspond of an additional daily production in the niobium circuit of $0.58 \mathrm{t}$ from niobium concentrate.

\section{Conclusions}

The results from flotation batch tests showed that $\mathrm{BM}$ presented the higher mass recovery and production capacity. However, the metal losses in beneficiation process
Table 4. Flotation tests results for OX, TM and BM

\begin{tabular}{cccc}
\hline \% & OX & TM & BM \\
\hline Mass Recovery & 10.0 & 10.0 & 9.0 \\
Global Recovery & 39.0 & 37.0 & 53.0 \\
Niobium oxide & 0.33 & 0.60 & 5.92 \\
Mass Feed & 4.50 & 1.00 & 5.00 \\
\hline
\end{tabular}

Table 5. Niobium production changing the cut-size feed

\begin{tabular}{ccc}
\hline \multirow{2}{*}{ Capacity } & \multicolumn{2}{c}{ Cut-size $(\boldsymbol{\mu m})$} \\
\cline { 2 - 3 } & $\mathbf{1 4 9}$ & $\mathbf{2 1 2}$ \\
\hline Niobium production (t/day) & 5.00 & 5.46 \\
\hline
\end{tabular}

Table 6. Mineralogical analysis resume from Niobium circuit feed adding Barite concentrate

\begin{tabular}{ccc}
\hline Capacity & $\begin{array}{c}\text { Niobium Circuit } \\
\text { Feed }\end{array}$ & $\begin{array}{c}\text { Adding Barite } \\
\text { Concentrate }\end{array}$ \\
\hline Total feed $(\mathrm{t} / \mathrm{h})$ & 125.0 & 164.0 \\
Niobium production $(\mathrm{t} /$ day) & 5.00 & 5.58 \\
\hline
\end{tabular}

can masked this potential. Only with the microscopy analysis results from plant survey samples it was possible to identify the reason of this possible losses and identify an opportunity to increase the niobium production. The niobium observed in the $\mathrm{BC}$ stage sample was lost because the Ba-pyrochlore was dragged together a barite and apatite crystals because most of them are in a size less than $38 \mu \mathrm{m}$. In NF stage sample, the problem was identified in the sieve, because according the mineralogical analysis the Ba-pyrochlore that feeds the plant had about $212 \mu \mathrm{m}$ as cut size, but the circuit is constituted by screens with $149 \mu \mathrm{m}$ aperture resulting in $60 \%$ of these minerals being discarded.

The results indicated an increase in niobium circuit production about $1.04 \mathrm{t} /$ day from niobium concentrate, being $0.58 \mathrm{t} /$ day from barite concentrate niobium recovery and $0.46 \mathrm{t} /$ day from changing the cut-size of the niobium circuit feed.

The geometallurgy program was fundamental to quantify the niobium ore available in the deposit and to generate information of great importance for mapping of process opportunities aiming to increase niobium recovery and production.

As suggestion for future studies the magnetic tailings shall be investigated by analysing the assays per size fraction and trying to optimize the recovery of valuable minerals using classification stages.

\section{Acknowledgements}

The authors would like to thank CMOC for permitting the publishing of the results from the Catalão circuit. 


\section{References}

1 Dunham S, Vann J. Geometallurgy, geostatistics and project value: does your block model tell you what you need to know? Parkville: AusIMM; 2007. p. 189-196. (Australasian Institute of Mining and Metallurgy Publication Series).

2 Walters S. An overview of new integrated geometallurgical research. In Proceedings of the International Congress for Applied Mineralogy; 2008 September 8-10; Brisbane, Australia. Melbourne: Australasian Institute of Mining and Metallurgy; 2008. p. 79-82.

3 Turner-Saad G. Vision for a risk adverse integrated Geometallurgy Framework. In Proceedings of the 42nd Annual Canadian Mineral Processors; 2010; Ottawa, Canada. Ottawa: Canadian Institute of Mining, Metallurgy and Petroleum; 2010. p. 156.

4 Lamberg P. Particles-the bridge between geology and metallurgy. In Konferens i Mineralteknik; 2011 February 8-9; Luleå, Sweden. Luleå: Luleå Tekniska Universitet; 2011.

5 Bye AR. Case studies demonstrating value from geometallurgy initiatives. In Proceedings of the International Geometallurgy Conference; 2011 September 5-7; Brisbane, Australia. Melbourne: Australasian Institute of Mining and Metallurgy; 2011. p. 3-90.

6 Dominy S, O’Connor L, Parbhakar-Fox A, Glass H, Purevgerel S. Geometallurgy: a route to more resilient mine operations. Minerals. 2018;8(12):560-593.

7 Cordeiro PFO. Petrology and metallogeny of the primary niobium deposit of the carbonatitic-phoscoritic complex of Catalão I [dissertation]. Brasília: Universidade de Brasília; 2009.

8 Lumpkin GR, Ewing RC. Geochemical alteration of pyrochlore group minerals: pyrochlore subgroup. The American Mineralogist. 1995;80:732-743.

9 Grasso CB. Geology and geometallurgy of phosphate ores at the base of the barreiro mine weathering mantle, Araxá, MG [thesis]. Brasília: Universidade de Brasília; 2015.

10 Rangel LV, Correia VAN, Milanezi BP, Mazzinghy DB, Filho AHPM. Geometallurgical characterization of nelsonite bodies from Catalão I carbonatitic complex to find favorable process targets. In Proceedings of the 5 th International Seminar of Geometallurgy - Geomet; 2018; Santiago, Chile. Santiago: Gecamin; 2018.

11 Rangel LV. Creation of a production and feed simulator from the phosphate and niobium plants in Catalão using geometallurgical information. In Proceedings of the $5^{\text {th }}$ International Seminar of Geometallurgy - Geomet; 2018; Santiago, Chile. Santiago: Gecamin; 2018.

Received: 14 Oct. 2019

Accepted: 13 Sep. 2020 